\title{
STUDI PENDAPATAN GAHARU (Aqularia sp) OLEH MASYARAKAT KAMPUNG HAHA DISTRIK SEREMUK KABUPATEN SORONG SELATAN
}

\author{
YOMIMA KEMESRAR ${ }^{1)}$ DAN PONISRI ${ }^{2)}$ \\ ${ }^{1}$ Mahasiswa S-1 Program Studi Kehutanan Universitas Muhammadiyah Sorong \\ ${ }^{2}$ Dosen Fakultas Pertanian Universitas Muhammadiyah Sorong
}

Diterima: 8 September 2017. Dipublikasikan: 1 Oktober 2017

\begin{abstract}
Abstrak
Penelitian ini bertujuan untuk mengetahui tingkat pendapatan masyarakat dari hasil penjualan kayu gaharu dan kualitas kayu gaharu yang dihasilkan oleh masyarakat di Kampung Haha Distrik Seremuk Kabupaten Sorong Selatan. Dari hasil penelitian bahwa tingkat pendapatan masyarakat dari hasil penjualan kayu gaharu di Kampung Haha Distrik Seremuk Kabupaten Sorong Selatan dengan pendapatan total bersih sebesar Rp. 30.887.000/bln dan pendapatan ratarata sebesar Rp. 3.088.700/bln. Tingkat kualitas kayu gaharu yang dihasilkan oleh masyarakat Kampung Haha Distrik Seremuk Kabupaten Sorong Selatan ada 7 yaitu kayu gaharu kelas super satu, super kelas dua, saba,medan batu, $\mathrm{AB}$ satu, $\mathrm{AB}$ dua dan kacang kruk.

Kata Kunci: Pendapatan, Gaharu, Kualitas
\end{abstract}

\section{PENDAHULUAN}

Indonesia merupakan negara kepulauan yang terletak di garis katulistiwa. Letak Indonesia yang berada di garis katulistiwa menjadikan Indonesia sebagai negara tropis dengan hutan tropis yang sangat kaya dalam hal keanekaragaman hayatinya. Dunia mengakui bahwa Indonesia juga memiliki potensi sumberdaya tumbuhan, baik sebagai penghasil kayu, juga tumbuhan berbagai ragam jenis penghasil non kayu yang memiliki nilai guna baik sebagai sumber bahan makanan, industrik maupun sebagai bahan obat herbal (Manan, 1998 dalam Sumarna, 2006). Salah satu jenis hasil hutan non kayu yang memiliki nilai guna sebagai bahan parfum, kosmetika dan sebagai obat herbal adalah gaharu (Heyne, 1987 dalam Sumarna, 2006). Gaharu diperoleh dari sejenis tumbuhan famili Thymeliaceae dan bermarga Aquilaria yaitu Aquilaria agaloccha Rox, namun gaharu dapat juga diperoleh dari famili Leguminoceae dan Euphorbiaceae. Saat ini gaharu (Aquilaria malaccensis) merupakan jenis yang paling baik dalam menghasilkan minyak gaharu (Sumarna,2009).Gaharu (Aquilaria malaccensis) merupakan salah satu tanaman kehutanan yang telah dikembangkan dengan teknik kultur jaringan. Tanaman ini merupakan salah satu hasil hutan non kayu Indonesia yang memiliki nilai jual yang sangat mahal. Potensi gaharu yang sangat tinggi biasanya berasal dari jenis A. malaccensis, A. hirta, A. macrophylum dll. Dan yang paling tinggi gaharunya adalah jenis $A$. malaccensis (Sumarna dan Santoso,2005). Papua yang memiliki potensi alam gaharu masih cukup tinggi dibandingkan dengan Kalimantan atau Sumatra (Sumarna 2007 dan Iranto, dkk 2010).Dimana gaharu dihasilkan oleh tumbuhan hutan yang mengalami pelapukan sebagai akibat terinfeksi jamur sehingga menghasilkan gubal yang mengandung damar wangi (aromatik resin) yang di perdagangkan sebagai bahan industri farfum, kosmetik dan obat-obatan. Gaharu yang diekspor di Indonesia berasal dari Sumatera, Kalimantan, Sulawesi, Nusa Tenggara dan Papua (Baharudin dan Taskirwati, 2009). Harga jual gaharu didalam negeri bervariasi tergantung kualitas misalnya pada awalnya tahun 2009 kualitas super dinilai dengan 350.000/kilogram (Rahma, 2012). Kawasan hutan di kampung Haha Distrik Seremuk Kabupaten Sorong Selatan memiliki tanaman penghasil gaharu yang potensinya cukup banyak. Namun informasi mengenai 
tingkat pendapatan dan kualitas kayu gaharu yang dibudidayakan oleh masyarakat setempat masih sangat kurang sehingga perlu dilakukan penelitian Tingkat Pendapatan dan Kualitas Kayu Gaharu oleh Masyarakat di Kampung Haha Distrik Seremuk Kabupaten Sorong Selatan.

\section{METODELOGI PENELITIAN}

\section{A. Tempat dan Waktu Penelitian}

Penelitian ini akan dilaksanakan pada hutan di Kampung Haha Distrik Seremuk Kabupaten Sorong Selatan dengan waktu penelitian kurang lebih 1 bulan yaitu dari bulan Juli-Agustus 2015.

\section{B. Alat dan Bahan Penelitian}

Adapun alat dan bahan yang digunakan dalam penelitian ini adalah sebagaiberikut

a. Kuisioner dan format isian untuk pengambilan informasi dari responden dan sumber data lainnya dari hasil observasi.

b. Kamera foto untuk memvisualisasikan kondisi fisik dan sosial di lapangan,terutama objek-objek penting dalam penelitian ini.

c. Alat-alat tulis, kalkulator, komputer dan kelengkapan lainnya untuk mengolahdata dan menyusun laporan penelitian.

Obyek dalam penelitian ini adalah masyarakat kampung Haha yang memanfaatkan kayu gaharu untuk dijual dalam menunjang ekonomi.

\section{Metode Penelitian}

Metode yang digunakan dalam penelitian ini adalah metode observasi dan survey dengan tehnik wawancara langsung di lapangan. Untuk pengambilan data responden dilakukan secara purposive sampling terhadap masyarakat yang memanfaatkan kayu gaharu untuk dijual.

\section{Variabel Penelitian}

Variabel dalam penelitian ini adalah :

1. Tingkat pendapatan masyarakat di Kampung Haha dari hasil penjualan kayu gaharu.

2. Kualitas kayu gaharu yang dihasilkan di Kampung Haha Distrik Seremuk Kabupaten Sorong Selatan.

\section{E. Prosedur Penelitian}

\section{Orientasi Lapangan}

Orientasi lapangan dilaksanakan untuk mengetahui gambaran dan keadaan umum lokasi penelitian.

2. Penentuan Jumlah Responden

Populasi dari penelitian ini adalah seluruh masyarakat yang ada di sekitar kawasan hutan. Adapun responden sebagai sampel dalam penelitian ini adalah masyarakat yang langsung memanfaatkan dan menjual kayu gaharu pada kampung Haha. Pemilihan responden untuk wawancara dilakukan secara purposive (purposive sampling), yang terdiri dari kepala keluarga, dan informan kunci (kepala desa, sekretaris desa, tokoh adat/masyarakat, dan kaur).

3. Pengambilan Data

Data dalam penelitian ini adalah data primer dan data sekunder .Data primer diperoleh melalui wawancara langsung pada responden dengan bantuan daftar pertanyaan yang sudah dipersiapkan. Data primer meliputi data sosial ekonomi masyarakat (pendapatan masyarakat, mata pencaharian, pendidikan), frekuensi pengambilan, lama dan waklu pengambilan, cara pemasaran kayu gaharu yang diperoleh. Biaya yang meliputi biaya transportasi, konsumsi, peralatan dan biaya lainnya yang dikeluarkan untuk mengambil kayu gaharu .Data sekunder diperoleh dari instansi terkait meliputi data kondisi umum lokasi penelitian.

\section{F. Analisis Data}

Perhitungan tingkat pendapatan masyarakat dari hasil penjualan kayu gaharu dari data lapangan hasil kuisioner dapat ditabulasikan berdasarkan karateristiknya. Data-data tersebut kemudian dianalisis secara kuantitatif dan kualitatif yang disajikan dalam bentuk tabel dan gambar. Data mengenai jumlah pemungut kayu gaharu serta jumlahnya yang didapat dari hasil wawancara dapat dihitung dengan menggunakan rumus menurut Lahjie (2010) sebagai berikut:

\section{Pendapa $\tan$ Total $(P T)=P X Q$}

Keterangan: $\mathrm{P}=$ Harga per kilogram

$\mathrm{Q}=$ Jumlah produksi yang dijual

BiayaTotal $(B T)=T C+V C$ 
Keterangan: $\mathrm{TC}=$ Total Cost $\mathrm{VC}=$ Varibel Cost (Biaya Variabel)

Pendapatan bersih $=$ PT - BT

\section{HASIL DAN PEMBAHASAN}

\section{A. Tingkat Pendapatan Masyarakat dari Hasil Penjualan Kayu Gaharu di Kampung Haha Distrik Seremuk Kabupaten Sorong Selatan}

Berdasarkan hasil penelitian dilapangan dari 10 responden yang diwawancara di kampung Haha Distrik Seremuk Kabupaten Sorong Selatan bahwa tingkat pendapatan masyarakat dari hasil penjualan kayu gaharu dapat dilihat pada Tabel 1 dibawah ini.

Tabel 1.Tingkat Pendapatan Masyarakat dari Penjualan Kayu Gaharu di Kampung Haha Distrik Seremuk Kabupaten Sorong Selatan

\begin{tabular}{|c|c|c|c|c|c|c|}
\hline Responden & $\begin{array}{l}\text { Jenis Kayu } \\
\text { Gaharu }\end{array}$ & $\begin{array}{l}\text { Frekuensi } \\
\text { Pengambilan } \\
\text { /bln }\end{array}$ & $\begin{array}{l}\text { Jumlah Pendapatan } \\
\text { Kayu Gaharu dlm } 1 \\
\text { bln/kg }\end{array}$ & $\begin{array}{l}\text { Harga Kayu } \\
\text { Gaharu/kg } \\
\text { Rp }\end{array}$ & $\begin{array}{l}\text { Pendapatan } \\
\text { Pendapatan } \\
\text { Total (Rp) }\end{array}$ & $\begin{array}{l}\text { Pendapatan } \\
\text { Bersih (Rp) }\end{array}$ \\
\hline Jumlah & & & 32 & & 2.760 .000 & 2.178 .000 \\
\hline 2 & $\begin{array}{l}\text { Saba super } \\
\text { Super Kelas } \\
\text { dua } \\
\text { AB dua } \\
\text { Kacang Kruk }\end{array}$ & 2 & $\begin{array}{c}2 \\
2 \\
5 \\
18\end{array}$ & $\begin{array}{l}200.000 \\
200.000 \\
95.000 \\
50.000\end{array}$ & $\begin{array}{l}400.000 \\
400.000 \\
475.000 \\
900.000\end{array}$ & 1.693 .000 \\
\hline $\begin{array}{l}\text { Jumlah } \\
4\end{array}$ & $\begin{array}{l}\text { Super kelas } \\
\text { Satu } \\
\text { Saba Super } \\
\text { Medan Batu } \\
\text { AB dua } \\
\text { Kacang kruk }\end{array}$ & 3 & $\begin{array}{c}33 \\
3 \\
5 \\
4 \\
3 \\
13\end{array}$ & $\begin{array}{l}250.000 \\
200.000 \\
150.000 \\
95.000 \\
50.000\end{array}$ & $\begin{array}{l}2.510 .000 \\
750.000 \\
1.000 .000 \\
600.000 \\
285.000 \\
650.000\end{array}$ & $\begin{array}{l}2.240 .000 \\
2.749 .000\end{array}$ \\
\hline Jumlah & & & 34 & & 4.750 .000 & 4. 366.000 \\
\hline 6 & $\begin{array}{l}\text { Super satu } \\
\text { Medan Batu } \\
\text { AB dua } \\
\text { Kacang Kruk }\end{array}$ & 3 & $\begin{array}{c}11 \\
6 \\
6 \\
18\end{array}$ & $\begin{array}{l}200.000 \\
150.000 \\
95.000 \\
50.000 \\
\end{array}$ & $\begin{array}{l}2.750 .000 \\
900.000 \\
570.000 \\
900.000\end{array}$ & 4.634 .000 \\
\hline Jumlah & & & 47 & & 5.120 .000 & 4.634 .000 \\
\hline 7 & $\begin{array}{l}\text { Saba Super } \\
\text { Medan Batu } \\
\text { Kacang Kruk } \\
\end{array}$ & 2 & $\begin{array}{l}18 \\
25 \\
12 \\
\end{array}$ & $\begin{array}{l}200.000 \\
150.000 \\
50.000 \\
\end{array}$ & $\begin{array}{l}1.600 .000 \\
1.250 .000 \\
1.800 .000 \\
\end{array}$ & 4.216 .000 \\
\hline Jumlah & & & 55 & & 4.650 .000 & 4.216 .000 \\
\hline 8 & $\begin{array}{l}\text { Super dua } \\
\text { Saba Super } \\
\text { AB dua }\end{array}$ & 3 & $\begin{array}{l}9 \\
6 \\
6\end{array}$ & $\begin{array}{l}200.000 \\
200.000 \\
95.000\end{array}$ & $\begin{array}{l}1.800 .000 \\
1.200 .000 \\
570.000\end{array}$ & 3.827 .000 \\
\hline
\end{tabular}




\begin{tabular}{|c|c|c|c|c|c|c|}
\hline & Kacang Kruk & & 15 & 50.000 & 750.000 & \\
\hline Jumlah & & & 36 & & 4.320 .000 & 3.827 .000 \\
\hline \multirow[t]{3}{*}{9} & Super dua & 2 & 8 & 250.000 & 1.600 .000 & 2.716 .000 \\
\hline & $\mathrm{AB}$ satu & & 9 & 100.000 & 900.000 & \\
\hline & Kacang kruk & & 15 & 50.000 & 750.000 & \\
\hline Jumlah & & & 32 & & 3.250 .000 & 2.716 .000 \\
\hline \multirow[t]{4}{*}{10} & Saba Super & 3 & 6 & 200.000 & 1.200 .000 & 2.268 .000 \\
\hline & Medan Batu & & 5 & 150.000 & 750.000 & \\
\hline & $\mathrm{AB}$ satu & & 4 & 100.000 & 400.000 & \\
\hline & Kacang Kruk & & 8 & 50.000 & 400.000 & \\
\hline Jumlah & & & 23 & & 2.750 .000 & 2.268 .000 \\
\hline $\begin{array}{l}\text { Jumlah } \\
\text { Pendapata } \\
\text { n Total } \\
\text { Bersih }\end{array}$ & 30.887 .000 & & & & & \\
\hline $\begin{array}{l}\text { Rata-rata } \\
\text { Pendapata } \\
\text { n Bersih }\end{array}$ & 3.088 .700 & & & & & \\
\hline
\end{tabular}

Berdasarkan tabel 1 di atas bahwa jenis kayu gaharu yang didapat yaitu super kelas satu, super kelas dua, saba super, medan batu, AB satu, AB dua dan kacang kruk. Dan pendapatan total bersih untuk 10 responden sebesar Rp. 30.887.000/bulan, sedangkan rata-rata pendapatan bersih responden sebesar Rp. 3.088.700/bulan. Dengan masing-masing frekuensi pengambilan kayu gaharu 2 sampai 3 kali dalam satu bulan serta hasil yang didapat antara 23 sampai $55 \mathrm{~kg} /$ bulan. Dimana hasil tersebut tergantung dari proses pencarian dan pengumpulan kayu gaharu, ini yang bersifat untung-untungan sehingga dalam upaya pencarian atau pengumpulan tersebut masyarakat pencari tidak menpunyai target tertentu yang disepakati, baik dari segi waktu maupun jumlah gaharu yang di kumpulkan.

Proses pengambilan kayu gaharu yang dilakukan oleh masyarakat kampung Haha yaitu dengan cara menebang pohon menggunakan kapak, setelah itu di kupas menggunakan parang untuk mengambil gubal gaharu yang berkualitas tinggi antara lain super kelas satu, super kelas dua, saba super, medan batu, $\mathrm{AB}$ satu, $\mathrm{AB}$ dua. Sedangkan sisa-sisa gubal gaharu yang masih menempel pada bagian kayu dikeruk menggunakan alat krok kayu sehingga didapatkan jenis kayu gaharu yang berkualitas rendah yaitu kacang kruk.

Kayu gaharu yang sudah diambil tersebut tidak dapat langsung dijual tetapi membutuhkan waktu 1-2 minggu untuk membersihkan dan menjemur agar tetap awet setelah itu siap untuk dijual. Harga yang ditetapkan berdasarkan kesepakatan antara pembeli dan penjual. Harga dikampung berbeda dengan harga di kota sehingga masyarakat lebih cenderung untuk menjual kayu gaharu di kota dari pada menunggu ditempat. Dengan harga masimg-masing kayu gaharu sesuai kualitasnya yaitu kayu gaharu super klas satu Rp. 250.000, Super klas dua Rp. 200.000, Saba Rp. 200.000, Medan Batu Rp. 150.000, AB Satu Rp. 100.000, AB dua Rp. 95.000 dan Kacang kruk Rp. 50.000.

Gaharu di kampung Haha adalah salah satu hasil hutan bukan kayu (HHBK) dengan berbagai bentuk dan warna yang khas serta memiliki kandungan damar yang beraroma khas damar wangi. Damar ini berasal dari jenis pohon penghasil kayu gaharu sebagai akibat adanya proses infeksi alami yang disebabkan oleh jamur Fusarium lateritium dan jamur Popolaria sp. Jenis-jenis pohon penghasil gaharu berbeda-beda untuk setiap daerah.

Khusus daerah Papua, pohon penghasil gaharu adalah spesies aroma spesifik yang dihasilkan oleh gaharu dapat dipergunakan untuk parfum, dupa, hio, obat-obatan dan pengharum ruangan. Sedangkan daun dan buah pohon penghasil gaharu dapat dipergunakan sebagai obat malaria (Biro, 2012). Selain itu pohon gaharu mempunyai fungsi ekologis dan aspek konservasi tanah dan air, karena pohon ini mempunyai tajuk yang rapat dan sistem perakaran yang dalam. 
Sistem pengusahaan atau tataniaga gaharu, petani pengumpul yang memperoleh gaharu di alam mempunyai dua kemungkinan hubungan dalam menjual kayu yang diperolehnya kepada pengusaha, yaitu yang bersifat mutlak dimana petani pengumpul (masyarakat) harus menyerahkan hasil perolehannya kepada pengusaha/pedagang yang telah mempunyai hubungan ikatan kontrak dengan pengusaha/pedagang tersebut, hal ini dilakukan sebelum proses pencarian kayu gaharu. Sedangkan kemungkinan kedua adalah hubungan tidak mutlak dimana petani pengumpul biasanya tidak mempunyai hubungan ikatan kerja dengan pengusaha/pedagang. Dalam hal ini petani pengumpul bebas melakukan proses pencarian kayu gaharu dan dapat menjual dengan bebas yang biasanya langsung dijual ke kota.

Sistem budidaya pohon gaharu di kampung Haha sudah mulai berkembang, namun kegiatan masyarakat dalam mencari gaharu di hutan alam masih cukup tinggi sehingga menyebabkan potensi pohon gaharu semakin berkurang. Dengan kondisi demikian maka potensi untuk pengembangan tanaman gaharu di kampung Haha sangat baik dan sangat potensial untuk dikembangkan, karena kawasan hutan kampung Haha merupakan sebaran habitat tempat tumbuh pohon gaharu. Oleh karena itu pengembangan gaharu di kampung Haha cukup prospektif karena kawasan hutannya merupakan daerah endemic pertumbuhan gaharu. Sebagian besar potensi sebaran pohon gaharu berada pada kawasan hutan alam dan hutan ulayat masyarakat setempat. Pengembangan budidaya inilah yang diharapkan dapat meningkatkan pendapatan masyarakat, penyerapan tenaga kerja dan sebagai kontribusi pendapatan daerah bagi pemerintah daerah.

Hal ini karena permintaan pasar terhadap gaharu terus meningkat. Selain kebutuhan peribadatan berberapa agama, gaharu juga digunakan oleh masyarakat Arab untuk sebagai siwak. Kondisi iklim yang panas dan kegemaran mengkonsumsi daging membuat tubuh mereka bau menyengat sehingga wangi gaharu digunakan sebagai pangharum (Jayadi, 2013).

Harga gaharu terus meningkat seiring dengan permintaan pasar, namun ketersediaan gaharu dari alam terus menurun, hal inilah yang mendasari budidaya gaharu. Harga gaharu super pada tahun $20014-5 \mathrm{jt} / \mathrm{kg}$, saat ini melambung menjadi $10-15 \mathrm{j} t / \mathrm{kg}$. Tapi sayang, peluang seperti ini Cuma diketahui oleh beberapa gelintir orang saja. Adapun negara tujuan eksport gaharu diantaranya adalah Singapura, Timur Tengah, Taiwan, Jepang, Hongkong, Korea dan Malaysia. Adapun eksport terbanyak ke negara Singapura baru Timur Tengah di urutan ke-2 (Trubus, 2014).

\section{B. Kualitas Kayu Gaharu yang Dihasilkan oleh Masyarakat Kampung Haha Distrik Seremuk Kabupaten Sorong Selatan}

Dari hasil wawancara dengan responden di Kampung Haha Distrik Seremuk yang mengusahakan kayu maka diperoleh beberapa kualitas kayu gaharu yang dapat dilihat pada Tabel 2 di bawah ini.

Tabel 2. Tingkat Kualitas Kayu Gaharu yang Dihasilkan oleh Masyarakat Kampung Haha Distrik Seremuk Kabupaten Sorong Selatan

\begin{tabular}{lll}
\hline No & $\begin{array}{l}\text { Tingkat Kualitas } \\
\text { Kayu Gaharu }\end{array}$ & Harga /Kg \\
\hline 1 & Super Kelas Satu & Rp. 250.000 \\
2 & Super kelas dua & Rp. 200.000 \\
3 & Saba Super & Rp. 200.000 \\
4 & Medan Batu & Rp. 150.000 \\
5 & AB satu & Rp. 100.000 \\
6 & AB dua & Rp. 950.000 \\
7 & Kacang Kruk & Rp. 50.000 \\
\hline
\end{tabular}

Berdasarkan Tabel 2 di atas bahwa kualitas kayu gaharu yang diperoleh masyarakat Kampung Haha Distrik Seremuk Kabupaten Sorong Selatan ada 7 jenis yaitu:

\section{Kayu Gaharu Super Kelas Satu}

Ciri-ciri kayu gaharu super kelas satu yaitu berwarna hitam merata, kandungan damar 
wangi tinggi, aroma kuat, dapat dilihat pada gambar 3 dibawah ini:

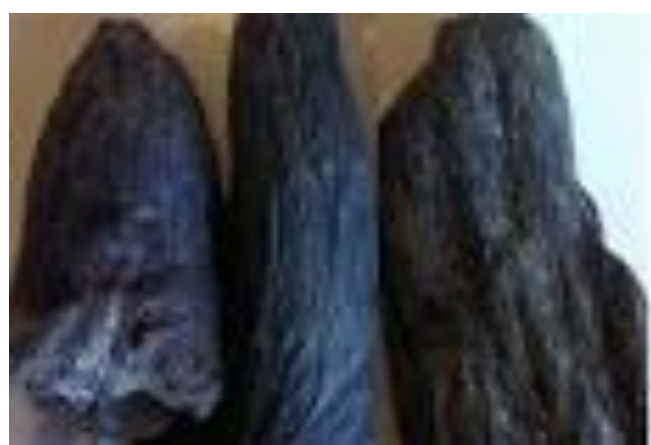

Gambar 1. Kayu Gaharu Super Kelas Satu

\section{Kayu Gaharu Super Kelas Dua}

Ciri-ciri gaharu super kelas dua yaitu berwarna hitam kecoklatan, kandungan damar wangi cukup, aroma kuat, dapat dilihat pada gambar 4 dibawah ini:

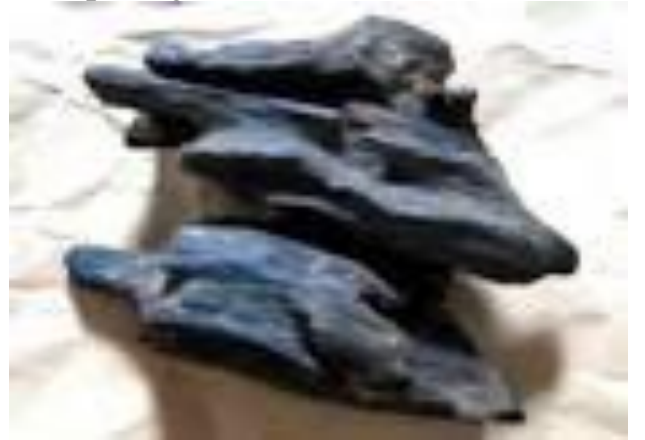

Gambar 2. Kayu Gaharu Super Kelas Dua

\section{Kayu Gaharu Saba Super}

Ciri-ciri gaharu Saba super yaitu berwarna hitam kecoklatan, kandungan damar wangi cukup, aroma agak kuat. Terdapat dari gaharu pohon gaharu hidup tetapi daunnya dan cabang-cabang pohon sudah gugur terlepas dari induk pohon gaharunya. Dapat dilihat pada gambar 5 dibawah ini:

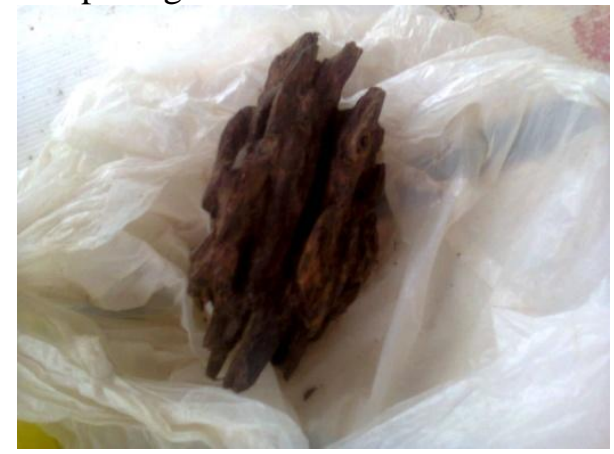

Gambar 3. Kayu Gaharu Saba Super
Ciri-ciri kayu gaharu medan batu yaitu berwarna coklat kehitaman, kandungan damar wangi sedang, aroma agak kuat adalah gaharu yang di ambil dari pohon gaharu hidup, yaitu bisa dilihat dari salah satu bagian pohon yang agak ketuaan lalu para pencari gaharu dapat menebang pohonnya untuk memecahkan dan mencari bagian-bagian pohon yang bergaharu. Dapat dilihat pada gambar 6 dibawah ini:

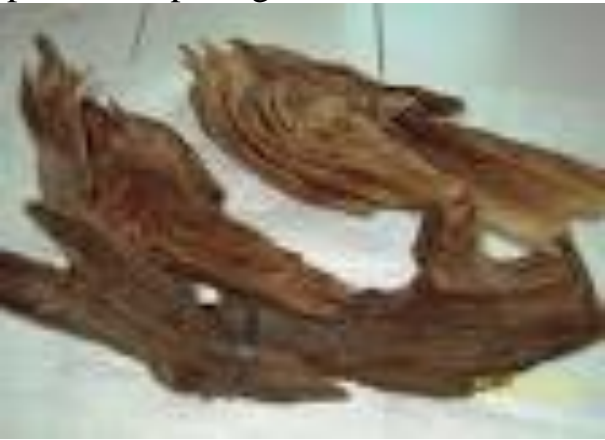

Gambar 4. Kayu Gaharu Medan Batu

\section{AB Satu}

Ciri-ciri kayu gaharu AB satu yaitu berwarna coklat kehitaman, kandungan damar wangi sedang, aroma kuat dapat dilihat pada gambar 7 dibawah ini:

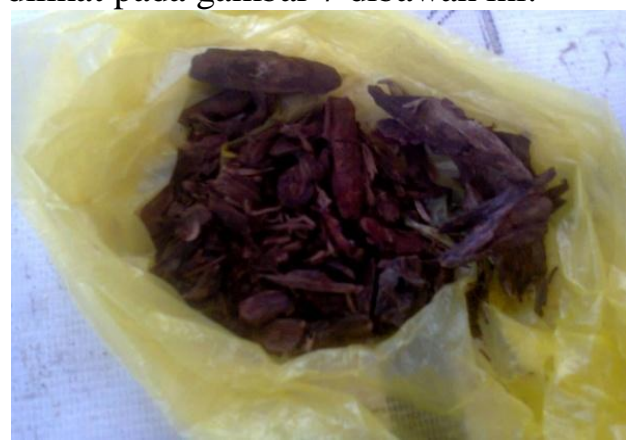

Gambar 5. Kayu Gaharu AB Satu

\section{AB Dua}

Ciri-ciri kayu gaharu $\mathrm{AB}$ dua yaitu berwarna coklat kehitaman, kandungan damar wangi sedang, aroma agak kuat, dapat dilihat pada gambar 8 dibawah ini:

\section{Kayu Gaharu Medan Batu}




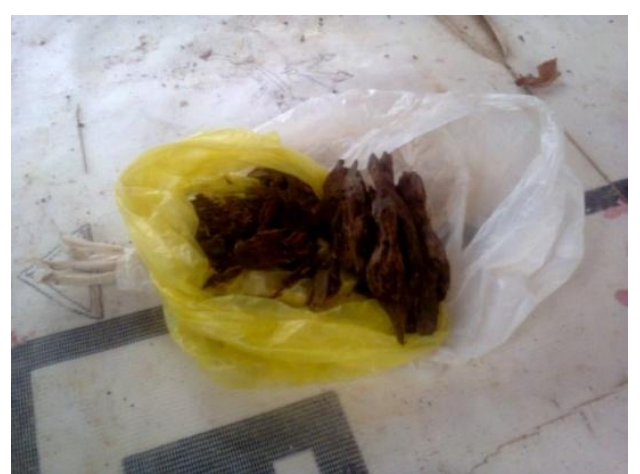

Gambar 6. Kayu Gaharu AB Dua

\section{Kacang Kruk}

Kacang kruk adalah merupakan potongan kayu kecil hasil pengerokan atau sisa penghancuran kayu gaharu yang berupa ampas-ampas gaharu potongan kayu kecil hasil pengkerokan. Dapat dilihat pada gambar 9 dibawah ini:

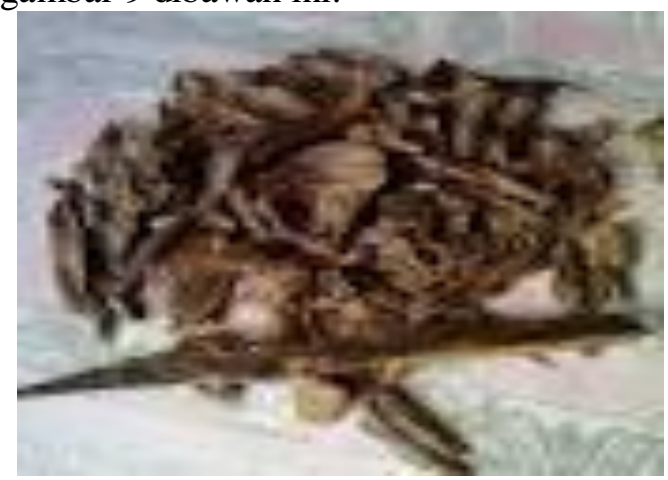

Gambar 7. Kayu Gaharu Kacang Kruk

Jenis-jenis kualitas gaharu di atas berasal dari satu pohon yang sama, masyarakat yang mencari kayu gaharu juga lincah untuk mengenal kualitas-kualitas gaharu yang siap di jual, antara lain masyarakat sudah membersihkan sekaligus sudah di pisah-pisahkan di antaranya ada gaharu super kelas satu, super kelas dua medan batu, Saba super, AB satu dan AB dua dan kacang kruk yang berasal dari pohon gaharu yang sama.

\section{PENUTUP}

\section{Kesimpulan}

Berdasarkan hasil penelitian dan uraian pembahasan maka dapat simpulkan an sebagai berikut:

1. Tingkat pendapatan masyarakat dari hasil penjualan kayu gaharu di Kampung Haha Distrik Seremuk Kabupaten Sorong Selatan dengan pendapatan total bersih sebesar Rp. 30.887.000/bln dan pendapatan rata-rata sebesar Rp. 3.088.700/bln.

2. Tingkat kualitas kayu gaharu yang dihasilkan oleh masyarakat Kampung Haha Distrik Seremuk Kabupaten Sorong Selatan ada 7 yaitu kayu gaharu kelas super satu, super kelas dua, saba,medan batu, AB satu, AB dua dan kacang kruk.

\section{Saran}

Dari hasil penelitian dapat disarankan perlu dilakukan sosialisasi dan penyuluhan yang dilakukan oleh dinas terkait kepada masyarakat agar masyarakat mulai dapat membudidayakan tanaman gaharu karena kayu gaharu dapat menunjang perekonomian bagi masyarakat dan menambah pendapatan daerah di Kampung Haha Distrik Seremuk Kabupaten Sorong Selatan.

\section{DAFTAR PUSTAKA}

BPS. 2007. Badan Pusat Statistik Kabupaten Sorong Selatan 2011 Papua Barat.

Biro. 2012 Kandungan dan Manfaat Gaharu di Indonesia http.//gaharuagrolestari.blogspot.co m/2011-06-01-archive. (diakses 1 Mei 2015).

Baharuddin dan Taskirawati, I., 2009.Buku Ajar Hasil Hutan Bukan Kayu. Fakultas Kehutanan Universitas Hasannudin.

Global Gaharu. 2012. Gaharu. Pontianak. Ggimepawah99.blogsopt.com/2012 . Diakses 6 Mei 2015.

Irianto, R.S.B., Santoso, Turjaman.M, dan Sitepu,I.R. 2010. Hama Pada Pohon Penghasil Gaharu dan Teknik Pengendaliannya.Jurnal Info Hutan Vol. VII No. 2:225-228.

Jayadi. 2013. Mengenal Jenis Dan Kayu Gaharu. Emashijauagarwood blogsopt.com/html diakses tgl 12 Mei 2015.

Lahjie, A.M. 2010. Valuasi Ekonomi Sumberdaya Alam Dan Lingkungan. Diktat Kuliah 
Pascasarjana

Universitas

Kehutanan.

Mulawarman.

Samarinda.

Martawijaya. 1989. Atlas Kayu Indonesia. Jilid II Badan Litbang Kehutanan. Bogor.

Sidiyasa, K. dan Suharti, S. 1998. Potensi Jenis Pohon Penghasil Gaharu. Proseding Lokakarya Pengembangan Tanaman Gaharu. Direktorat Jenderal Rehabilitasi Lahan Dan Perhutanann Sosial. Jakarta.

Sumarna, Y.2002. Budidaya Gaharu. Seri Agribinis. Penebar Swadaya. Jakarta.

Sumarna, Y. 2006. Teknik Budidaya dan Rekayasa Produksi Pohon Penghasil Gaharu. Puslitbang Hutan dan Konservasi Alam . Bogor.
Sumarna, Y. 2009. Gaharu Budidaya dan Rekayasa Produksi. Penerbit Penebar Swadaya.

Sumarna, Y. dan Santoso,E. 2005. Teknologi Budidaya dan Rekayasa Produksi Gaharu. Prosiding Temu Pakar Pengembangan HHBK. Direktorat Jenderal Rehabilitasi Lahan dan Perhutanan Sosial. Jakarta.

Trubus. 2011. Gaharu di Indonesia http://gaharuagrolestari.bloespot.co mi2011-06-01-archive. (diakses 1Mei 2015).

Trubus. 2014. Investasi Pohon Gaharu. Jenis Gaharu. Pohongaharu blogsopt.com/p/jenis-gaharu/html. Diakses tanggal 7 Juni 2015. 